\title{
LA NUEVA LEY
}

\section{NEW LAW}

\begin{abstract}
AUTORES
Juan José Ugalde Fernández: Profesor de Relaciones Públicas de la Facultad de Ciencias de la Información de la Universidad Complutense de Madrid (España). Autor de varios artículos sobre la reforma de la ley de enseñanza superior en España, conferenciante y ponente en numerosos congresos universitarios y especialista en comunicación corporativa.

juan.ugalde@ozu.es
\end{abstract}

\section{CURRÍCULUM VITAE}

Profesor de Relaciones Públicas de la Facultad de Ciencias de la Información de la Universidad Complutense de Madrid (España). Autor de varios artículos sobre la reforma de la ley de enseñanza superior en España, conferenciante y ponente en numerosos congresos universitarios y especialista en comunicación corporativa.

\section{RESUMEN}

Resumen de los artículos:

Resumen del Debate sobre la Ley Orgánica de Universidades,

La Comunidad Universitaria Alcalaína debate la Ley de Universidades,

Rechazo del Anteproyecto LOU 


\title{
PALABRAS CLAVE
}

Ley Orgánica de Universidades - Universidad de Alcalá - Ley de Universidades Anteproyecto LOU

\author{
ABSTRACT \\ Summary of Articles: \\ Summary Discussion of the Universities Act, \\ The discussion Alcala University Community Colleges Act, \\ Rejection of Draft LOU
}

\section{KEY WORDS}

Organic Law of Universities - University of Alcalá - Universities Act - Draft LOU

\section{ÍNDICE}

1. Resumen del Debate sobre la Ley Orgánica de Universidades

2. La Comunidad Universitaria Alcalaína debate la Ley de Universidades

3. Rechazo del Anteproyecto LOU 
1. Resumen del debate sobre la ley orgánica de universidades. Celebrado en Alcalá de Henares, el 26 de junio de 2001 (organizada por aula de debate universitario. aula magna $\mathrm{f}$. de económicas)

Intervención de ISMAEL CRESPO (Director General de Universidades del MEC)

- Oportunidad de la Ley: Declaración de Bolonia

- Situación en España: En 1983 había aprox. 700.000 estudiantes - ahora 1.500.000

- Previsiones 2010: 980.000

PROBLEMAS IDENTIFICADOS:

- Falta de agilidad de la gestión universitaria

- Selección del profesorado: Endogamia

- Movilidad de alumnos y profesores

- Sistema de acceso a la Universidad: Selectividad

- Evaluación de la calidad de las universidades

- Regulación de las universidades privadas

OBJETIVOS DE LA LEY:

- Calidad docencia, investigación y gestión

- Desarrollar mecanismos para potenciar la investigación

- Promover la integración en la UE

- Selección del profesorado por mérito y capacidad

Intervención de GABRIEL TORTELLA(Catedrático de la U.A y articulista) 
- LRU nació muerta. Pretendía una universidad que no es posible en España.

- La reforma se quedó corta.

- La universidad está muy mal administrada. Una vez que se administre bien se podrá pedir más dinero.

- Las becas deben darse exclusivamente por expediente académico, sin considerar nivel de ingresos.

- La endogamia ha llegado a extremos insostenibles.

Intervención de JUAN HERNÁNDEZ (Gerente Universidad de Jaén e investigador sobre gestión universitaria)

- No hay datos de la gestión ni rendimientos en las Universidades

- No hay nada que ocultar. No se hace tan mal. Muchos otros organismos, con mayores presupuestos, ni se han planteado analizar su eficacia o rendimientos.

- No cree que la Ley vaya a producir mejoras. Con el dinero que disponen las universidades ya lo hacen bastante bien.

- Han aumentado los costes pero no la financiación en igual medida.

- Debe revisarse la permanencia en la universidad de los alumnos que no aprueban y producen un gasto innecesario que pagamos todos.

- Los Consejos Sociales deben revisarse. Deben ejercer el control presupuestario y de la calidad.

- Los presupuestos deben contemplar los objetivos y también analizarse su consecución en los presupuestos.

Pulse este enlace para ver el documento, en formato PDF, que recoge las informaciones sobre el debate dadas por el Semanario "Puerta de Madrid" y el "Diario de Alcalá" 


\section{La comunidad universitaria alcalaína debate la ley de universidades}

El Gobierno espera que la Ley orgánica entre en vigor para el curso 2003-2004

\section{AULA DE DEBATE UNIVERSITARIO}

Un centenar de miembros de la comunidad universitaria de Alcalá, la mayoría claustrales de los distintos estamentos: catedráticos, titulares, personal y alumnos, debatieron, el 26 de junio pasado, sobre el controvertido proyecto de Ley Orgánica de Universidades que el Gobierno de la Nación pretende someter a trámite parlamentario antes de este mes de agosto.

El acto, convocado por la recientemente constituida AULA DE DEBATE UNIVERSITARIO, que promueven una treintena de universitarios alcalaínos y preside el profesor José Morilla, catedrático de Fundamentos e Instituciones Económicas y candidato al rectorado, contó con la presencia de todos los invitados anunciados: Ismael Crespo, Director General de Universidades (MEC) , Gabriel Tortella, catedrático de nuestra Facultad de Ciencias Económicas y reputado articulista sobre la materia, y Juan Henández Armenteros, actualmente gerente de la Universidad de Jaén y uno de los más citados investigadores de la gestión universitaria.

Durante casi cuatro horas desde las siete de la tarde, el Aula Magna de la Facultad de Económicas fue el espléndido escenario de un debate que la comunidad universitaria alcalaína venía demandando hace tiempo, y primero que se celebra en la Universidad de Alcalá. La presencia del Director General de Universidades fue saludada especialmente dada la coincidencia de fechas con el Debate del Estado de la Nación. El máximo representante ministerial en la materia, inició el turno de exposiciones desglosando los elementos fundamentales de esta Ley y la filosofía 
política de la misma. Gabriel Tortella, por su parte, elevó notablemente el tono polémico del debate con sus afirmaciones iniciales en las que cuestionaba el actual modelo financiero universitario, singularmente en lo relativo a las tasas, sobre lo que reclamó su adecuación al coste real (aproximadamente un millón por alumno), lo que luego, durante el turno de intervenciones del público, provocaría no pocas controversias. Juan Armenteros, a su vez, se proclamó conocedor a fondo de la materia, lo que ciertamente demostró en su intervención.

La presencia en la mesa de un representante del Gobierno y de un representante universitario andaluz dio pié a una polémica previsible sobre las funciones y responsabilidades del Estado y de las Comunidades Autónomas, al caso ejemplarizando sobre el modelo andaluz, lo que elevó aún más la intensidad de un debate moderado por el profesor José Morilla con tino y acierto. Ya en el turno de intervenciones del público tomaron la palabra una treintena de los presentes que calentaron aún más el ambiente de esta calurosa tarde de junio. En el aire, numerosas propuestas, planteamientos y algunas preguntas: la comunidad universitaria alcalaína expresó sus inquietudes respecto a los grandes temas que ahora se debaten con la misma intensidad en foros universitarios y en medios de comunicación en todo el país. Algunos catedráticos, profesores titulares, personal laboral y alumnos tuvieron ocasión de exponer sus planteamientos en presencia del propio Director General, de un candidato a rector presente en la mesa, y del propio rector alcalaíno en ejercicio, Manuel Gala, que presenció el debate desde las sillas del público una vez incorporado al mismo.

Al filo ya de la medianoche, los bares circundantes a la Facultad de Económicas recibieron a los más pertinaces que agotaron todas las oportunidades ofrecidas por el encuentro con el Director General. Un periodista de agencia no dudó en preguntar al representante ministerial sobre los tiempos de esta Ley, y específicamente sobre su posible afectación a las próximas elecciones al rectorado de la Universidad de Alcalá. 
En las propias palabras del Director General, esa elección se realizará por el método estatutario vigente (elección por el Claustro), dado que la implantación de la Ley y sus transitorias no será efectivo hasta el curso 2003-2004, según las previsiones del propio Gobierno, indistintamente de que se pretenda que la Ley Orgánica pueda ser formalmente aprobada en el primer semestre del año próximo, conforme también a la voluntad del Gobierno de la Nación.

\section{Rechazo del Anteproyecto LOU}

Estimados compañeros:

Os enviamos este documento para ver si se lo podéis hacer llegar al profesorado de vuestra Universidad.

\section{Atentamente}

\section{María del Mar Noda Rodríguez}

Dpto. Sociología. Universidad de La Laguna.

E-mail: mmnoda@ull.es

Los abajo firmantes EXPONEN su rechazo al Anteproyecto de LOU porque:

Con los nuevos tipos de contratos se acentúa la precariedad del profesorado contratado tanto desde el punto de vista de la estabilidad como de la promoción.

Establece un modelo discutible de calidad docente e investigadora, al obligar a su personal contratado a una forzada movilidad geográfica. 
Introduce unos mecanismos de habilitación que suponen la vuelta a sistemas de oposición anacrónicos y superados por la LRU

Propone un modelo de profesor puramente como investigador, desde una perspectiva administrativista, centralista y jerárquica

\section{DEFIENDEN:}

Un modelo de calidad docente e investigadora sustentado en la estabilidad y en la promoción del profesorado contratado en cada universidad.

Unas prácticas de formación del alumnado universitario respetuosa con la diversidad, tanto de las distintas titulaciones y universidades como de las diferentes comunidades autónomas.

La conformación de equipos estables de investigación.

La defensa de la autonomía de las universidades, entre otras cosas, para contratar, evaluar y promocionar a su personal docente e investigador

\section{EXIGEN:}

La articulación de los procesos legales necesarios para garantizar dichos principios.

si estás de acuerdo con lo anteriormente expuesto, te rogamos nos envíes, lo antes posible, un correo electrónico a una de las siguientes direcciones:

Cperez@ull.es <mailto:Cperez@ull.es>

Bezamora@ull.es <mailto:Bezamora@ull.es> 
Mmnoda@ull.es<mailto:Mmnoda@ull.es>

Rellenando los siguientes datos:

Nombre y apellidos:

Categoría:

Area de conocimiento:

Facultad, Escuela Universitaria o Centro Superior:

Universidad:

E-Mail:

Gracias por vuestra colaboración 